\title{
TRYPANOSOMES FOUND IN A COW IN ENGLAND.
}

\author{
By ALFRED C. COLES, M.D., D.Sc., F.R.S. ED., M.R.C.P. LoND.
}

\section{(With Plate XII.)}

History. Trypanosomes have been cultured from the blood of cattle in many parts of the world; in Germany, Denmark, Greece, Holland, France, Russia, Japan, the Philippines, Siberia, Algeria, Tunis, the United States and Brazil. But in only a few cases have the actual parasites been found in the circulating blood. From the scanty literature at my disposal, but especially from the Sleeping Sickness Bulletin, I find that the following observers have found and described the trypanosomes in the blood.

S. Stockman (1910) inoculated ten pedigree English cattle going to South Africa with Piroplasma. Nine of them showed piroplasms in their red corpuscles. In the blood films of six of these trypanosomes were found, in one instance nine days after the inoculation, and noted for a period of eight days.

The length of the parasite was about $50 \mu$, the breadth $2 \cdot 5 \mu$. The posterior extremity was pointed, and at the anterior end there was a long flagellum. The undulating membrane was very distinct. Stockman states that the parasite is not to be distinguished morphologically from Trypanosoma theileri. Attempts at cultivation on artificial media failed. He points out that the discovery suggests that some of the British blood-sucking ties may be capable of acting as true carriers of trypanosomes.

Frank, in July 1908, whilst examining some pathological material from an ox sent from Westerwald and suspected to contain B. anthracis, found actively motile trypanosomes. These were characterised especially by the drawn out and pointed posterior end resembling a flagellum.

M. Mayer (1910) points out that this belongs to the T. theileri group which vary in length from $30-70 \mu$. 
Knuth and Rauchbaar (1910) examined 69 smears taken from 97 animals, 48 of which were cattle, to see if they could find T. franki, but with negative results.

Peter (1910), whilst Veterinary Surgeon to Liebig's Extract of Meat Co. in Uruguay, from 1904-1909, found trypanosomes in cattle. These had the following characters. Length $30-60 \mu$. The aflagellar end is sharply pointed, in the larger forms long and beak-like, in the smaller short and hook-shaped. The blepharoplast is longish or round and is sometimes near the posterior end, sometimes near the nucleus. The nucleus lies exactly in the middle of the body: it is most frequently oval in shape and placed somewhat obliquely, or it is round. The free part of the flagellum attains the length of $15 \mu$. Multiplication stages are seldom seen in the circulating blood. Most of the cattle were Herefords or Shorthorns. The natural infection was found in seven cattle and in each case the disease was detected in the slaughter-house, the presence of a splenic tumour ieading to the examination of the blood and spleen pulp. In two instances piroplasmata were found as well as trypanosomes: the latter were always very scarce. Peter (1910) would place this trypanosome in the T. theileri group.

Paul Behn (1910), during researches on the trypanosomes occurring. in German cattle, in which Knuth, Rauchbaar and Morgenstern showed the presence of trypanosomes by cultural methods, found a large trypanosome in a cow. Its total length was $55 \mu$, breadth $12 \mu$, free flagellum $12 \mu$. The macronucleus was placed transversely, with the blepharoplast situated $4 \mu$ behind it. Behn was unable to find another individual in this preparation in spite of long examination.

Wrublewski (1908) described a trypanosome found in the blood of a dead Lithuanian bison.

Harold Crawley (1912) under the name of "Trypanosoma americanum, a common Blood parasite of American cattle," describes trypanosomes which he obtained by cultural methods from cattle in the United States. An attempt was made to discover the trypanosome in freshly drawn blood which was centrifuged, and preparations were obtained in which the leucocytes were as abundant as the red corpuscles. Six different animals were used, and a large number of fresh preparations were examined, but no trypanosomes were ever found: this nevertheless is believed to be the most efficient method. When, however, stained smears were examined trypanosomes were found in two slides out of $\mathbf{2 5}$. Crawley gives the following description of the trypanosomes. "As to the morphology of the blood forms, a selection of 14 gave an average 
measurement of $16.8 \times 3.8 \mu$. The trypanosomes in the circulating blood probably have a length of at least $20 \mu$, excluding the flagellum, and this was the size of the trypanosome that was found in the first day culture."

Principal characteristics of Trypanosoma americanum (from the Sleeping Sickness Bulletin, Vol. IV, p. 150): "It is a large trypanosome: a total length of $75 \mu$ is by no means uncommon. The undulating membrane is very short: the kinetonucleus may be in front, alongside or behind the trophonucleus, but the two are always close together. The trophonucleus is at the junction of the anterior and middle thirds: hence the shortness of the undulating membrane."

As to the rarity of the trypanosomes, the author writes-" Here it is seen that the smallest quantity of blood to give a positive result was five drops, or 03375 c.c., and that this result was obtained only once out of three trials. Assuming 6,000,000 red cells and 10,000 leucocytes per cubic millimetre, we find as a possible proportion one trypanosome for 2,022,000,000 red cells and 3,370,000 whites. Hence to find the trypanosome in the circulating blood would be merely a piece of good fortune. Further, culture 444, containing 9 c.c. of blood, was negative, yet this amount of blood contains $90,000,000$ leucocytes."

Trypanosomes found in a Cow. For some considerable time I have been making a systematic examination of the blood of domestic animals, small mammals, birds, fish, etc., and I asked my friend Mr J. S. Wood, Veterinary Surgeon, of Parkstone, to send me any blood films from diseased animals and particularly from cases of redwater fever in cattle. These films were received air dried, unfixed and unstained, and were afterwards stained with Giemsa's stain. I should like here to express my thanks to $\mathrm{Mr}$ Wood for the trouble he has taken on my behalf.

After a large number of blood films had been examined with negative results, I received from $\mathrm{Mr}$ Wood four films taken at 9.30 a.m., June 3, from a cow presenting symptoms of redwater fever. These films showed the presence of Piroplasma bovis in comparatively small numbers, only about $2 \%$ of the red corpuscles being infected. (I say a small percentage, as during $1906 \mathrm{I}$ received blood films from $\mathrm{Mr}$ T. B. Goodall taken from a cow with redwater fever, in which $23 \frac{1}{2} \%$ of the corpuscles contained Piroplasma.)

1 See Trypanoplasma sp. Bowhill, 1909, and T. rutherfordi Hadwen, 1912, observed in Cows at Mount Lehman, British Columbia (Watson and Hadwen, Parasitology, this vol. p. 24, Feb. 1912). Ed. 
The cow from which Mr Wood obtained the blood films was a Shorthorn about eight years old, from a farm in Dorset. On June 2nd and 3rd the urine was of a deep red colour, but during the latter day it became almost clear, being only slightly tinged.

In the evening of June 3rd at 6 p.m. four more films were taken. These were, as Mr Wood says, very badly and unevenly spread, as the cow was very restless.

These seven films were systematically examined and in one of them a perfect trypanosome was found. Subsequently in the same preparation another trypanosome was also found showing considerable distortion.

On June $6 \mathrm{Mr}$ Wood took me over to see the cow and I made about 20 more films, but after a prolonged examination no more trypanosomes were detected.

Description of the Trypanosome. The parasite has the form of an almost perfect $\mathbf{S}$, being thickest in the middle of the body and tapering towards both extremities.

The Body is stained a deep violet-blue colour with Giemsa and is filled with minute granules closely packed together in all but the extremities, which are quite free from granules for about $10 \mu$ in the anterior end and for about 8 or $9 \mu$ in the posterior end. The thickest part of the body is about the region of the nucleus, but it continues at the same width for about $16 \mu$, after which it gradually tapers towards the extremities, both of which terminate in fine points, especially the anterior or flagellar end. There is no difficulty in determining the exact point at which the anterior extremity of the body ceases and the free portion of the flagellum begins.

The somewhat abrupt termination of the granular protoplasm of the body gives an impression of the posterior extremity being merely a sheath. There are no indications of myonemes, although some of the granules are arranged somewhat longitudinally.

The undulating membrane is thrown into a number of folds and is stained a pale lilac colour, in which the granules are loosely scattered in marked contrast to their compact arrangement in the body.

The undulating membrane is bounded by a very distinct border, the attached part of the flagellum, whilst the free portion of the latter is short, measuring only about $10 \mu$. The trophonucleus is situated almostly exactly at the middle of the body. Its greatest diameter lies transversely to the long axis of the parasite. It measures $6 \mu$ by $3 \cdot 3 \mu$. Its shape is somewhat like the letter B, the anterior border being 
straight, the posterior thrown into two slight curves. It stains a pale red colour with Giemsa. The margins are surrounded by granules, which are arranged somewhat loosely, giving the impression, so often seen in the trypanosomes of birds, of being surrounded by a lighter stained area. No definite internal structure can be made out.

The kinetonucleus is a very insignificant looking structure by no means easily seen. It is round, deeply stained, and lies in an area in which there are fewer granules. It is situated about $5 \mu$ from the centre of the nucleus, and has a diameter of about $1 \cdot 2 \mu$.

It is by no means easy to trace the attached portion of the flagellum directly to the kinetonucleus, although there are areas of fewer granules along its path.

The distorted trypanosome differs considerably in its general appearance from that described above. As will be seen from the figure, it is a large stumpy form, but during the preparation of the film its posterior extremity has been crushed and therefore it is impossible to give any accurate description. In this individual the flagellum does not seem to run up to the kinetonucleus but stops a short distance in front of it, the interval being made up by an exceedingly fine line which can be recognised in the photograph.

The dimensions of the perfect trypanosome are as follows: total length, $98 \mu$; length of body, $88 \mu$; free flagellum, $10 \mu$; distance from posterior extremity to kinetonucleus $37 \mu$, and to the centre of trophonucleus, $44 \mu$; distance between trophonucleus and kinetonucleus, $5.5 \mu$; diameter of body at trophonucleus, $6 \mu$, together with the undulating membrane, $9 \cdot 5 \mu$.

In conclusion I should like to express my thanks to Mr J. W. Ogilvy and $\mathrm{Mr} \mathrm{Wm}$. Harding for their kindness in taking the microphotographs.

\section{REFERENCES.}

BeHN, P. (1910). Ueber Entwicklungsformen des Trypanosoma franki. Berliner tierärztliche Wochenschrift, XXVI, 809-810.

Crawliy, H. (1912). The Protozoan Parasites of Domesticated Animals. Bureau of Animal Industry, U.S. Department of Agriculture. Report No. 27 (for the year 1910), pp. 184-187.

Frank, G. (1909). Ueber den Befund von Trypanosomen bei einem in Stein-Wingert (Westerwald, Regierungsbezirk Wiesbaden) verendeten Rinde. Zeitschr. f. Infektionskrankh. paras. Krankh. u. Hyg. d. Haustiere, v, 313-315.

KNuth, P. and RauchbaAR, G. (1910). Zum Vorkommen von Trypanosomen bei Rindern in Deutschland. Berl. tieräratl. Wochenschr. xxvI, 609. 
Mayen, M. (1909). Ueber Trypanosoma theileri und diesem verwandte Rindertrypanosomen. Zeitschr. f. Infektionskrankh. paras. Krankh. u. Hyg. d. Haustiere, vI, 46-51.

Peter, O. (1910). Morphologische und experimentelle Studien über ein neues, bei Rindern in Uruguay (Süd-Amerika) gefundenes Trypanosoma. Beiheft z. Arch. f. Schiffs- $u$. Tropenhygiene.

Stockman, S. (1910). Preliminary Note on a Trypanosome of British Cattle. Journ. Comp. Path. and Therapeutics, xxIII, 189-192.

Wrublewski, K. J. (1908). Ein Trypanosoma des Wisent von Bielowesch. Centralbl. f. Bakteriologie, Orig. xuvII, 162-163. 
PARASITOLOGY, VOL. V. NO. 4

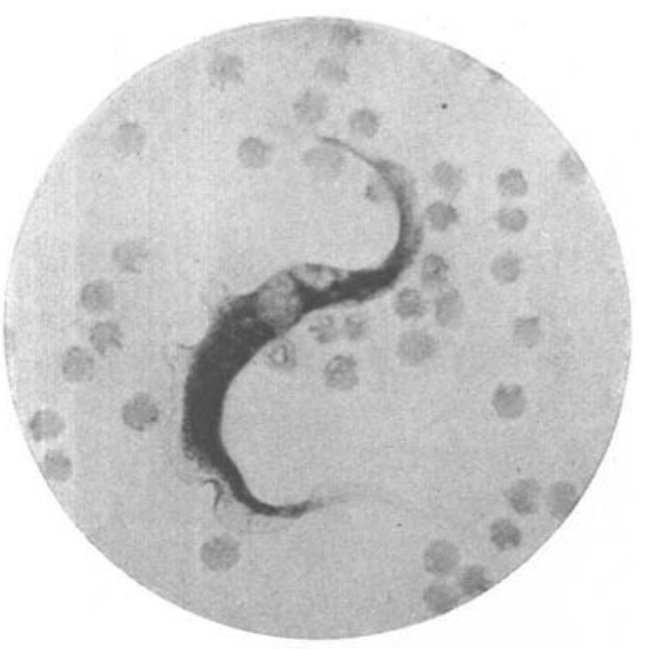

Fig. 1. Trypanosome of cow. ( $\times 1000$.

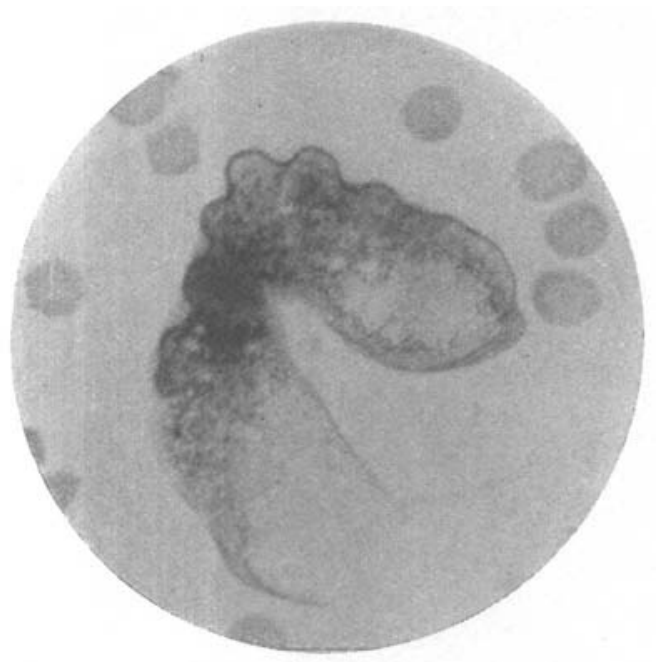

Fig. 2. Distorted stumpy form. ( $\times$ 1000.) 


PARASITOLOGY, VOL. V. NO. 4

PLATE XIII

w. Vintor. 